\title{
Speaking Hebrew to Individuals in a Group: Psycho Logical Incompatibility and Processing Coast
}

\author{
Ordit Elisheva Tranto, Yuval Wolf \\ Bar-Ilan University, Ramat Gan, Israel \\ Email: orditelisheva@gmail.com
}

How to cite this paper: Tranto, O. E., \& Wolf, Y. (2020). Speaking Hebrew to Individuals in a Group: Psycho Logical Incompatibility and Processing Coast. Psychology, 11, 1890-1909.

https://doi.org/10.4236/psych.2020.1112120

Received: November 3, 2020

Accepted: December 19, 2020

Published: December 22, 2020

Copyright $\odot 2020$ by author(s) and Scientific Research Publishing Inc. This work is licensed under the Creative Commons Attribution International License (CC BY 4.0).

http://creativecommons.org/licenses/by/4.0/

\section{(c) (i) Open Access}

\begin{abstract}
Hebrew speakers cannot address directly individuals within a group. This derives from the prevalent use of the second person plural masculine form, which abandons individuals' identity. The use of masculine form as a default makes it especially difficult for females. These psycho logical characteristics of Hebrew require individual listeners within a group to process an instantaneous correction: males, from plural form to singular and females, from plural to singular and from masculine to female. Two reaction time (RT) experiments were purported to examine cognitive implications of these characteristics for speakers of Hebrew as L1. Each participant was required to respond promptly to a series of 60 nouns in Hebrew, equally divided between second person singular and second person plural male form. In Experiment 1 it took longer for each of the 57 adults ( 30 men, 27 women) to respond to the second person plural masculine form. Women's RT in such conditions was longer. Experiment 2 found a similar trend, with greater RT, in 5 - 6-year-old children ( 15 boys and 15 girls). A new sub-field of cognitive research, which can be called "Psycho logical incompatibility" or "Corrective language processing", is suggested, depending on future support for the present findings.
\end{abstract}

\section{Keywords}

Second Person Plural Masculine Form, Second Person Singular Masculine Form, Psycho Logical Incompatibility, Reaction Time, Corrective Language Processing

\section{Introduction}

Hebrew is the bible language and for nearly two thousand years, it was used 
mainly for Jewish religious necessities. Namely, it did not undergo any substantive evolution as many other languages did, for example English. At the onset of the $20^{\text {th }}$ century, Hebrew became a living language and since 1948 it became the main formal language of the state of Israel. Quite a few functional aspects of this language were revived, especially on the lexical level. Nevertheless, one psychologically important aspect of Hebrew did not undergo any change. Namely, a person who speaks to individuals in a group has to adhere to the default of doing it in a second person plural masculine form. Assumingly, this facilitates a development of correcting process in speakers of Hebrew as a first language, which has important psychological reflections and implications, as discussed below.

When a person speaks in Hebrew to a group of speakers of Hebrew as first language (hence L1) but refers to any individual within the group, for instance saying "מה אתם חושבים?" (Imagine) or "תארו לעצמכם" (Imat do you think?), he or she is using Second person plural masculine (hence SPPM), simply because this sort of speech is Hebrew's default for such occasions (Tobin, 2001). Hebrew (and possibly other languages such as Arabic) does not equip anyone speaking to individuals within a group with linguistic means to refer to the listeners as individuals. There is no formal way to use in such occasions second person singular form and no way to get beyond the male default as well. Evidently, in Hebrew there is no detour-like solution such as "imagine" or "you" in English.

The rationale of this study is based on the presumption that the cognitive system of any user of Hebrew as L1 can't operate as a part of grouped mechanism (Beebe \& Lachmann, 1988; Terry, Hogg, \& White, 1999). Hypothetically, a correcting mechanism, from SPPM to second person singular muscular form (hence SPSM), develops during the process of acquisition of Hebrew as L1. Since masculine form is a default in Hebrew, the development of a twofold correction is expected in females-from plural form to singular and from masculine to feminine (Arnold, Eisenband, Brown-Schmidt, \& Trueswell, 2000; Schmitt, Lamers, \& Munte, 2002).

These hypotheses, if viable, should facilitate quite a few applied implications for speakers of Hebrew as L1 as discussed at the end of this composition. To mention but a few, all of them should feel uncomfortable being referred to in terms of SPPM. Some sub-conscious barrier between feminine self-image and own L1 should be developed, as well as unease for the repeated brain-washing deliberated to put men as the preferable gender. Hypothetically, these psycho logical characteristics of Hebrew require any individual listener within a group to process an instantaneous correction: males, from plural to singular, and females from plural to singular and from masculine to feminine (Tranto \& Wolf manuscript). A new sub-field of cognitive research, which can be called "Corrective language processing", is suggested at the end of this composition, based on the results of the present study.

Survey evidence illustrates the extent to which this form of speech prevails in settings where speakers attempt to address individuals within a group. For ex- 
ample, of 40 weekly TV Hebrew episodes of the children's series called Dora (a Hebrew dubbing of the English version), 87\% of all second person appeals were made in the second person plural masculine form, whereas the English version of the same series used second person plural (gender-neutral) forms such as "you or "look". Another source of evidence for the mundane validity of this phenomenon comes from recordings of classes in Hebrew from 105 elementary school teachers in Israel (ref). It was found that $97.68 \%$ of second person appeals were second person plural masculine. A similar survey among 18 college lecturers yielded comparable results: $91.05 \%$ of second person appeals were second person plural masculine.

The present study focuses on the way in which this uniqueness of Hebrew is reflected in cognitive processing of such speakers' appeals. Hypothetically, an appeal to an individual which implies that he or she should assume a collective processing mechanism, should be conceived as (psycho)logically inappropriate. Spoken language is by and large understood in a non-literal manner during conversation (e.g. Austin, 1962; Searle, 1965; Grice, 1967). According to Wilson \& Sperber's (2006) "relevance theory" there must be sufficient linguistic evidence regarding "correct" linguistic constructions if they are to be understood. These authors as well as others (Clark \& Lucy, 1975), assume that during conversation human consciousness naturally searches for meaning, and both speaker and listener seek contextual relevance spontaneously and actively. Empirically, it was found that 2 - 16 sentences out of 100 are "corrected" during natural speech and that such alterations can be done while speaking (Kasl \& Mahl, 1987).

In order to understand the connotation of a message, inferences beyond literal meaning must be drawn, and in terms of cognitive processing, comprehension is a form of problem solving that occurs unknowingly (Clark \& Lucy, 1975) This includes grasp of context, activation of general knowledge and judgment about the speaker's beliefs, on the background of tacit agreement shared between speaker and listener, which lead to quick and efficient understanding of meanings.

Studies that explore the resolution of formal ambiguous pronouns, which rely on event-related brain potentials (ERPs), explore how listeners and readers comprehend pronouns. An important issue has been whether pronouns and antecedents are promptly matched on syntactic features like number and gender (Arnold et al., 2000; MacDonald \& MacWhinney, 1990; Schmitt et al., 2002). Another thoroughly investigated issue comprises the strategies that readers and listeners opt for, when they may engage in optional strategic processing to identify the referent of an ambiguous pronoun (Jarvikivi et al., 2005). Further research focuses on the potential differences in how ambiguous pronouns are resolved formally (Nieuwland \& Van Berkum, 2006).

"He" or "she" are much less frequent in such cases (Baranowski, 2002). According to Meyers (1990), this genderless singular pronoun becomes an integral part of the American lexicon, despite its being ungrammatical. In an experiment conducted by Foertsch and Gernsbacher (1997), using eye movement, found 
"processing cost" of the use of singular "they" in various contexts in terms of reading time (slower). These results coincide with those of Kerr \& Underwood (1984), which focused on pronouns that were inconsistent with expectations. Possibly, the use of "they" implies that the writer or speaker is trying to conceal the gender of the person being talked about, which is likely to give the reader or listener pause.

The American Psychological Association specifies that "Each pronoun should refer clearly to its antecedent and should agree with its antecedent in gender and number". Alas, in spoken language "them" is frequently used to refer to singular antecedents (Singular-them) (Baranowski, 2002). This can be demonstrated with sentences such as "I stopped someone and asked them for directions". This sentence is grammatically faulty due to the mismatch in number between antecedent and pronoun. Doherty and Conklin (2017) found that sensitivity to the use of "them" referred to high expectancy and gender-known antecedents in offline and online measures, as well as effortless integration of "them" when it is used to refer to low expectancy antecedent. While the absence of an antecedent causes processing disruption in the singular pronoun cases, there is no disruption in the plural (they) cases.

Sanford, Sanford, Emmott, and Morrow (2010) propose that if a singular pronoun fails to identify an explicitly specified antecedent there is a disruption to processing. Sanford and Filik (2007) tested the effects of genderless referential plural antecedents with that of genderless singular referential antecedents using eye detection. They found that plural pronouns create less processing disruption in the context of plural antecedents than in the context of genderless singular antecedents.

Priming effects are attributable to the direct association between first-person pronouns and attention mechanisms. Findings suggest that first-person pronouns activate either individualistic or collectivistic self, and the induced self, in turn, primes the corresponding attention system (Na \& Choi, 2009). Kashima and Kashima (1998), found that the ease of dropping pronouns in a language is an important indicator of individualism and collectivism. It is easier (and more frequent) to drop a pronoun in languages of collectivistic cultures (possibly Hebrew) than in languages of individualistic cultures (possibly English). People in collectivistic cultures often drop pronouns in conversation to reduce tension and maintain interpersonal harmony (Kashima \& Kashima, 1998).

The present study attempts to contribute to the research on speech cost and processing cost by focusing on the psychologically illogical messages in Hebrew which imply collective "self" and "mind", since Hebrew lacks a linguistic means to enables speakers to address individuals within a group (Tobin, 2001). Thus, "םrebrew native speakers resort to the second person plural masculine form " as a default in addressing both male and female individuals within a group. Hebrew simply does not have a gender-neutral pronoun such as the English "you”.

The default use of the second person plural masculine pronoun, i.e. "אתם" ("you”), when referring to an individual within a group, disregards the basic as- 
sumption regarding the "self" as an undisputable psychological concept (Stern, 1985). A baby is born with subjective sense of self. The self develops via an intersubjective relationship with significant others (e.g. mother and father), and those relationships are referred to as a "self-object". From a psychological perspective, a person cannot forego the fundamental need to exist as an entity separate from the rest of the world. The distinct self is preserved through close relationships with significant others and through the gradual development of social belonging (Winnicott, 1960).

Therefore, it is psychologically improper for a person to become one with a given group of people, as suggests the use of second person plural form. Rather, an effort is always made (albeit unconsciously) to maintain the "self" as a basic ingredient of healthy psychological existence (Kraut, 1973). The "self" can't be set aside at the expense of communication routines. Such practice discounts the elementary universal need to remain a separate and unique being within a social-cultural environment (Ziller, 1973; Winnicott, 1960).

With regard to gender, in Hebrew the masculine form applies to a person and to an object as well. The female form applies only when the sentence addresses only a female. Ariel and Giora (1998) found that children who speak Hebrew as a first language (hence L1) relate to the masculine form as the default or generic form. Generally, in Hebrew, the use of the word "אתם" ("you" plural masculine) and any other forms of second person plural masculine form are very common. This routine in Hebrew prevails in both spoken and written practice. Learning how to distinguish between literal and conveyed meaning involves diverse social learning processes, the present study focuses on one of them, i.e., instantaneous and unconscious cognitive transformation of PP into the appropriate singular form.

We assume a longitudinal learning process that manifests itself in terms of an automatic cognitive correction mechanism (ACM). Hypothetically, ACM is activated when a Hebrew listener is required to respond to a PP request. The time lapse from the onset of the verbal address to the listener's response (RT) should be a function of the complexity of the in-between processing (Jiang, 2012), in other words-a speech cost. A relatively shorter RT is expected when the second person single pronoun (hence SP) "התא") you) is used to address individuals within a group. That is since there is no need of correction, as should be the case when the PP form is used. RT in this case should be modified as a function of learned adaptation processes.

An ACM represents a unique linguistic phenomenon (Blackmer \& Mitton, 1991) that develops through spontaneous operant learning since early childhood (Bandura, 1986), whereby the listener is continually influenced by incidental unnoticeable gestures made by the very many speakers in the history of the child as a listener. Hypothetically, an automatic cognitive mechanism develops with the passage of time, the function of which is turning "אתה" (SPPM) into" (SPSM) or "את" (SPS female) to meet the un-negotiable need for personal acknowledgment. Based on the above literature, he following hypotheses are proposed: 
1) The use of PP is expected to elicit a correction process, which should be reflected in longer RT as compared to SP.

2) Addressing a woman or a girl by the PP form should trigger a twofold correction-to switch from plural to singular form and to shift from masculine to feminine gender. Hence females' RT [PP - SP] should be longer than those of males in similar conditions.

3a) The automatic correction mechanism in Hebrew is presumed to develop over time as a part of language learning. Hence, it is hypothesized that children's correction time in terms of RT should be longer than that of adults.

3b) Girls' correction time in terms of RT should be longer than that of boys.

\section{Experiment 1: Men's and Women's RTs in Response to Messages with Plural and Singular Forms of Address}

\section{Method}

Participants in Experiment 1 were 30 men and 30 women, 30 - 38-year-old ( $M$ $=\mathrm{xx}$ ), from varied white-collar occupational backgrounds (e.g. high-tech, teaching, secretarial work), all of whom spoke Hebrew as a native language. Each participant signed a consent form after being assured of anonymity. The study was approved by the University's Ethics Committee. Each participant was tested individually. He or she was exposed to 60 requests in Hebrew, presented one at a time and ordered randomly, to think of or imagine simple and commonly used objects.

Half of the requests (30) were phrased in PP form and half (30) in SP form (e.g., "חופת וניימד" (imagine masc.pl) or "חופת ויימד" (imagine masc.sing an apple)). The experiment was conducted in a private in the experimenter's office or home. At the end of each session, each participant was debriefed about the purposed of the experiment.

The participant was seated in front of a PC terminal and prior to detailed instructions for the experiment, a sort of task deception took place. The participant was told that other participants are exposed to the same procedure at the same time. Then the participant was asked to imagine a commonly used object (i.e., imagine an apple) and to press a button attached to a Serial Response Box ("E-Prime 2.0). E-prime computes and records RTs in milliseconds (Jiang, 2012). Response timebegan from the end of the experimenter's request to the participant and ended when the participant pressed the response button as indication that the request had been fulfilled. Upon conclusion of the experiment, each participant was asked to comment on his or her experience, and to report on any thoughts generated by the experiment.

\section{Results and Discussion}

Men. As an example of the raw data collected at the individual level Table 1 shows the RTs of two male participants for all 60 stimuli (30 PP and 30 SP). The mean PP - SP differences for the two participants (over the 30 pairs of stimuli) were 104 and $94 \mathrm{msec}$. In line with Hypothesis 1, RTs in conditions of PP were 
Table 1. Original RT scores of two randomly selected participants.

\begin{tabular}{|c|c|c|c|c|c|c|}
\hline \multicolumn{4}{|c|}{ Participant 3} & \multicolumn{3}{|c|}{ Participant 25} \\
\hline participant & difference & plural & single & difference & plural & Single \\
\hline 1 & -92.00 & 2005.00 & 2097.00 & 66.00 & 3090.00 & 3014.00 \\
\hline 2 & 430.00 & 2395.00 & 1965.00 & 937.00 & 3155.00 & 2218.00 \\
\hline 3 & 355.00 & 2584.00 & 2229.00 & 218.00 & 3131.00 & 2913.00 \\
\hline 4 & 503.00 & 2678.00 & 2175.00 & 474.00 & 2481.00 & 2007.00 \\
\hline 5 & -43.00 & 2490.00 & 2533.00 & 418.00 & 2132.00 & 1714.00 \\
\hline 6 & -101.00 & 2339.00 & 2440.00 & 133.00 & 2371.00 & 2238.00 \\
\hline 7 & 127.00 & 2381.00 & 2254.00 & -201.00 & 2013.00 & 2215.00 \\
\hline 8 & 366.00 & 2554.00 & 2188.00 & -107.00 & 2062.00 & 2169.00 \\
\hline 9 & -274.00 & 2361.00 & 2635.00 & 159.00 & 2118.00 & 1959.00 \\
\hline 10 & 311.00 & 2380.00 & 2069.00 & -180.00 & 1929.00 & 2109.00 \\
\hline 11 & -89.00 & 2177.00 & 2266.00 & 470.00 & 2418.00 & 1948.00 \\
\hline 12 & -174.00 & 2190.00 & 2364.00 & 415.00 & 2231.00 & 1816.00 \\
\hline 13 & 272.00 & 2312.00 & 2040.00 & 256.00 & 2499.00 & 2243.00 \\
\hline 14 & 332.00 & 2161.00 & 1829.00 & -673.00 & 2379.00 & 3052.00 \\
\hline 15 & 143.00 & 2150.00 & 2007.00 & 533.00 & 2853.00 & 2320.00 \\
\hline 16 & 93.00 & 2228.00 & 2135.00 & -539.00 & 1975.00 & 2514.00 \\
\hline 17 & 140.00 & 2151.00 & 2011.00 & 70.00 & 2031.00 & 1961.00 \\
\hline 18 & -445.00 & 1993.00 & 2438.00 & 27.00 & 2157.00 & 2130.00 \\
\hline 19 & 161.00 & 2267.00 & 2106.00 & 76.00 & 2337.00 & 2261.00 \\
\hline 20 & -114.00 & 2191.00 & 2305.00 & 540.00 & 2729.00 & 2189.00 \\
\hline 21 & -291.00 & 2010.00 & 2301.00 & -346.00 & 2221.00 & 2567.00 \\
\hline 22 & 109.00 & 2114.00 & 2005.00 & 55.00 & 2150.00 & 2095.00 \\
\hline 23 & 286.00 & 2327.00 & 2041.00 & 84.00 & 2043.00 & 1959.00 \\
\hline 24 & -389.00 & 2097.00 & 2486.00 & -221.00 & 2143.00 & 2364.00 \\
\hline 25 & 19.00 & 2196.00 & 2177.00 & 144.00 & 2283.00 & 2139.00 \\
\hline 26 & -88.00 & 2224.00 & 2312.00 & 322.00 & 1754.00 & 2432.00 \\
\hline 27 & 499.00 & 2448.00 & 1949.00 & -387.00 & 1938.00 & 2325.00 \\
\hline 28 & 207.00 & 2134.00 & 1927.00 & -1.00 & 2625.00 & 2626.00 \\
\hline 29 & 242.00 & 2515.00 & 2273.00 & 347.00 & 2479.00 & 2132.00 \\
\hline 30 & 641.00 & 2407.00 & 1766.00 & -256.00 & 2451.00 & 2707.00 \\
\hline average & 104.53 & 2281.96 & 2177.43 & 94.00 & 2372.60 & 2278.20 \\
\hline
\end{tabular}

longer than those for SP. The individual RT results for all 30 men confirmed this result, as reflected in the PP - SP difference, $2336.66-2255.03=81.67 \mathrm{~ms}, t(28)$ $=7.75, p<0.01$.

Overall, in line with Hypothesis 2, Table 2 shows that women's PP - SP RT difference was greater than men's (114 msec vs. $81.67 \mathrm{msec}=32.33), t(55)=$ 2.69, $p<0.01$. In terms of processing time, the results of Experiment 1 suggest that messages in Hebrew to individuals in a group require additional processing time as a precondition for response. 
Table 2. 30 men's RT means in the entire sets of $30 \mathrm{PP}$ and 30 SP conditions.

\begin{tabular}{|c|c|c|c|}
\hline participant & difference & plural & singular \\
\hline 1 & 72.50 & 2308.00 & 2235.50 \\
\hline 2 & 71.50 & 2247.50 & 2176.00 \\
\hline 3 & 119.50 & 3256.00 & 3136.50 \\
\hline 4 & 9.50 & 2482.00 & 2472.50 \\
\hline 5 & 56.50 & 2938.50 & 2882.00 \\
\hline 6 & 54.50 & 2579.00 & 2524.50 \\
\hline 7 & 89.00 & 2763.00 & 2474.00 \\
\hline 8 & 155.00 & 2402.00 & 2247.50 \\
\hline 9 & 123.00 & 2112.00 & 1989.50 \\
\hline 10 & 100.50 & 2950.50 & 2850.00 \\
\hline 11 & 112.00 & 2084.00 & 1972.00 \\
\hline 12 & 82.00 & 2520.00 & 2438.00 \\
\hline 13 & 51.50 & 2795.00 & 2744.00 \\
\hline 14 & 107.50 & 2046.00 & 1938.50 \\
\hline 15 & 25.00 & 1803.00 & 1778.00 \\
\hline 16 & 123.50 & 1975.50 & 1852.00 \\
\hline 17 & 85.00 & 2286.50 & 2201.50 \\
\hline 18 & 95.00 & 2084.50 & 1989.50 \\
\hline 19 & 125.50 & 2264.50 & 2139.00 \\
\hline 20 & 98.50 & 1897.50 & 1799.00 \\
\hline 21 & 93.00 & 2304.00 & 2211.00 \\
\hline 22 & 24.50 & 2451.50 & 2427.00 \\
\hline 23 & 94.00 & 2310.00 & 2216.50 \\
\hline 24 & 171.00 & 2398.00 & 2227.00 \\
\hline 25 & 13.50 & 2381.50 & 2368.00 \\
\hline 26 & 64.00 & 1691.00 & 1627.00 \\
\hline 27 & 68.50 & 1999.50 & 1931.00 \\
\hline 28 & 29.00 & 2701.00 & 2672.00 \\
\hline 29 & 97.00 & 2272.00 & 2175.00 \\
\hline 30 & 38.50 & 1905.50 & 1957.00 \\
\hline average & 81.60 & 23340 & 2255.03 \\
\hline
\end{tabular}

Women. Three of the 30 women participants lost concentration during the experiment as evidence by very high RTs. They were therefore removed from the sample. Two out of the remaining 27 participants (no. 4 and no. 13) and their RT scores are presented for illustrative purposes in Table 3. The mean PP - SP RT difference for these two participants were 2381.6 and 2266.6, respectively. In Table 4, a similar trend was found for the results of all 27 women in Table 4, as reflected in their mean PP - SP difference, $2381.6-2266.6=115.00 \mathrm{msec}, t(25)$ $=114.00, p<0.01$.

Overall, in line with Hypothesis 2, women's PP - SP RT difference was greater 
Table 3. Original RT scores of two randomly selected participants.

\begin{tabular}{|c|c|c|c|c|c|c|}
\hline \multicolumn{4}{|c|}{ Participant 13} & \multicolumn{3}{|c|}{ Participant 4} \\
\hline participant & difference & plural & singular & difference & plural & singular \\
\hline 1 & -40.00 & 2193.00 & 2233.00 & -157.00 & 2317.00 & 2474.00 \\
\hline 2 & 582.00 & 2557.00 & 1975.00 & -123.00 & 2381.00 & 2504.00 \\
\hline 3 & 4.00 & 2404.00 & 2400.00 & -287.00 & 2356.00 & 2643.00 \\
\hline 4 & 474.00 & 2529.00 & 2055.00 & 426.00 & 3416.00 & 2990.00 \\
\hline 5 & -12.00 & 2253.00 & 2265.00 & 189.00 & 2984.00 & 2795.00 \\
\hline 6 & 38.00 & 2080.00 & 2042.00 & 694.00 & 2831.00 & 2137.00 \\
\hline 7 & -91.00 & 2118.00 & 2209.00 & 93.00 & 2399.00 & 2306.00 \\
\hline 8 & 248.00 & 2162.00 & 1914.00 & 255.00 & 2548.00 & 2293.00 \\
\hline 9 & 63.00 & 2145.00 & 2082.00 & 826.00 & 3294.00 & 2468.00 \\
\hline 10 & -107.00 & 2249.00 & 2356.00 & -653.00 & 2352.00 & 3005.00 \\
\hline 11 & 480.00 & 2585.00 & 2105.00 & -508.00 & 2946.00 & 3454.00 \\
\hline 12 & -230.00 & 2130.00 & 2360.00 & 272.00 & 2297.00 & 2025.00 \\
\hline 13 & 143.00 & 2490.00 & 2347.00 & -656.00 & 2564.00 & 3220.00 \\
\hline 14 & -650.00 & 2234.00 & 2299.00 & 569.00 & 3678.00 & 3109.00 \\
\hline 15 & 470.00 & 2389.00 & 1919.00 & 1153.00 & 3973.00 & 2820.00 \\
\hline 16 & 239.00 & 2179.00 & 1940.00 & 276.00 & 3021.00 & 2745.00 \\
\hline 17 & -39.00 & 2053.00 & 2092.00 & 704.00 & 3050.00 & 2346.00 \\
\hline 18 & 362.00 & 2256.00 & 1894.00 & 129.00 & 2226.00 & 2097.00 \\
\hline 19 & 157.00 & 2301.00 & 2144.00 & 841.00 & 2669.00 & 1828.00 \\
\hline 20 & 105.00 & 2004.00 & 1899.00 & 532.00 & 2931.00 & 2399.00 \\
\hline 21 & 305.00 & 2324.00 & 2019.00 & -212.00 & 2147.00 & 2359.00 \\
\hline 22 & 185.00 & 2069.00 & 1884.00 & -158.00 & 1834.00 & 1992.00 \\
\hline 23 & 5.00 & 2173.00 & 2168.00 & 3.00 & 2272.00 & 2269.00 \\
\hline 24 & -68.00 & 1929.00 & 1997.00 & 49.00 & 2049.00 & 2000.00 \\
\hline 25 & -109.00 & 2317.00 & 2426.00 & 539.00 & 2483.00 & 1944.00 \\
\hline 26 & 233.00 & 2054.00 & 1821.00 & 470.00 & 2406.00 & 1936.00 \\
\hline 27 & -2.00 & 2198.00 & 2200.00 & 8.00 & 2219.00 & 2211.00 \\
\hline 28 & 309.00 & 2446.00 & 2137.00 & 21.00 & 2227.00 & 2206.00 \\
\hline 29 & 371.00 & 2488.00 & 2117.00 & -82.00 & 2087.00 & 2169.00 \\
\hline 30 & -58.00 & 2231.00 & 2289.00 & 320.00 & 2343.00 & 2023.00 \\
\hline average & 131.73 & 2251.33 & 2119.60 & 184.43 & 3610.00 & 2425.56 \\
\hline
\end{tabular}

than men's $(114.00-81.67=32.33), t(55)=2.69, p<0.01$. The results of Experiment 1 suggest in terms of processing time differences that messages in $\mathrm{He}$ brew to individuals in a group facilitate an extra processing time as a precondition for response, possibly as an automatic correction from PP to SP. Moreover, another sort of extra processing time takes place when a woman is the receiver of that sort of communication.

Experiment 2, detailed below, was a replication of Experiment 1, adapted to preschool children (5 - 6 years old). This part of the present study was intended 
Table 4. 27 women's RT means in the entire sets of $30 \mathrm{PP}$ and $30 \mathrm{SP}$ conditions.

\begin{tabular}{|c|c|c|c|}
\hline participant & difference & plural & singular \\
\hline 1 & 107.00 & 2632.00 & 2525.00 \\
\hline 2 & 118.00 & 2198.00 & 2080.00 \\
\hline 3 & 134.00 & 2021.00 & 1887.00 \\
\hline 4 & 184.00 & 2610.00 & 2426.00 \\
\hline 5 & 79.00 & 2109.00 & 2030.00 \\
\hline 6 & 148.00 & 2993.00 & 2845.00 \\
\hline 7 & 101.50 & 2961.50 & 2860.00 \\
\hline 8 & 57.00 & 2674.00 & 2617.00 \\
\hline 9 & 85.00 & 1872.00 & 1787.00 \\
\hline 10 & 103.00 & 1836.00 & 1733.00 \\
\hline 11 & 127.50 & 2369.50 & 2242.00 \\
\hline 12 & 81.00 & 2932.00 & 2851.00 \\
\hline 13 & 131.00 & 2251.00 & 2120.00 \\
\hline 14 & 80.00 & 2353.00 & 2273.00 \\
\hline 15 & 17.50 & 2128.50 & 2111.00 \\
\hline 16 & 55.00 & 2040.00 & 1985.00 \\
\hline 17 & 253.00 & 2651.00 & 2398.00 \\
\hline 18 & 190.00 & 3396.00 & 3206.00 \\
\hline 19 & 149.00 & 2329.00 & 2180.00 \\
\hline 20 & 161.00 & 2116.00 & 1955.00 \\
\hline 21 & 109.00 & 1969.00 & 1860.00 \\
\hline 22 & 89.00 & 2203.00 & 2114.00 \\
\hline 23 & 39.00 & 2091.00 & 2052.00 \\
\hline 24 & 69.00 & 2251.00 & 2182.00 \\
\hline 25 & 129.00 & 2629.00 & 2500.00 \\
\hline 26 & 122.50 & 2015.00 & 1892.50 \\
\hline 27 & 185.00 & 2673.00 & 2488.00 \\
\hline average & 114.96 & 2381.60 & 2266.60 \\
\hline
\end{tabular}

to obtain support for the prediction that RT traces of a spontaneous correction process in PP conditions can be found in early childhood, with greater inter-trial and inter-personal variance among children compared to adults.

\section{Experiment 2: Comparison of Preschool Childrens' RTs in Response to Messages with Plural and Singular Forms of Address}

The participants in Experiment 2 were 5 - 6-year-old 15 boys and 15 girls, from a kibbutz kindergarten, all of whom were native speakers of Hebrew. All aspects of Experiment 1 were replicated adapted to preschool children's understanding of the task. During the training stage, the experimenter introduced the task as a game of imagination and asked the child five times to imagine various objects. 
Once it was clear that the child understood, the child was given a set of headphones and told that instead of listening to the experimenter, he or she would hear the requests to imagine or to think of objects over the headphones. Next, the child was introduced to the use of the response button and received five practice trials. When the experimenter was convinced that the child understood the experimental requests, the experiment began.

\section{Results and Discussion}

Table 5 displays the RTs for a boy and a girl chosen to illustrate the raw data

Table 5. Original RT scores of two randomly selected children, a boy and a girl.

\begin{tabular}{|c|c|c|c|c|c|c|}
\hline \multicolumn{4}{|c|}{ Participant 5} & \multicolumn{3}{|c|}{ Participant 7} \\
\hline participant & difference & plural & singular & difference & plural & singular \\
\hline 1 & 714.00 & 2790.00 & 2076.00 & -522.00 & 3346.00 & 3896.00 \\
\hline 2 & 237.00 & 2454.00 & 2217.00 & -183.00 & 3685.00 & 3868.00 \\
\hline 3 & -2149.00 & 3025.00 & 5174.00 & -1443.00 & 2162.00 & 3605.00 \\
\hline 4 & 936.00 & 3476.00 & 2540.00 & -33.00 & 1912.00 & 1945.00 \\
\hline 5 & -187.00 & 3306.00 & 3493.00 & 514.00 & 2515.00 & 2001.00 \\
\hline 6 & -41.00 & 2803.00 & 2844.00 & 356.00 & 2152.00 & 1796.00 \\
\hline 7 & -323.00 & 2265.00 & 2588.00 & 1082.00 & 3193.00 & 2111.00 \\
\hline 8 & -342.00 & 1961.00 & 2304.00 & 609.00 & 2291.00 & 1682.00 \\
\hline 9 & -70.00 & 2097.00 & 2167.00 & -225.00 & 1934.00 & 2159.00 \\
\hline 10 & -111.00 & 2295.00 & 2406.00 & 884.00 & 3130.00 & 2246.00 \\
\hline 11 & 47.00 & 2248.00 & 2201.00 & -165.00 & 3084.00 & 3249.00 \\
\hline 12 & -39.00 & 2093.00 & 2132.00 & 750.00 & 3435.00 & 2685.00 \\
\hline 13 & 305.00 & 2171.00 & 1866.00 & 370.00 & 3044.00 & 2674.00 \\
\hline 14 & 751.00 & 2560.00 & 1809.00 & -713.00 & 2050.00 & 2763.00 \\
\hline 15 & 360.00 & 2396.00 & 2036.00 & 314.00 & 1928.00 & 1614.00 \\
\hline 16 & 75.00 & 1900.00 & 1825.00 & 272.00 & 2632.00 & 2360.00 \\
\hline 17 & 623.00 & 2311.00 & 1688.00 & 34.00 & 2001.00 & 1967.00 \\
\hline 18 & 63.00 & 2159.00 & 2096.00 & 268.00 & 2119.00 & 1851.00 \\
\hline 19 & 2944.00 & 5054.00 & 2110.00 & -508.00 & 2219.00 & 2727.00 \\
\hline 20 & 479.00 & 2321.00 & 1842.00 & -309.00 & 2347.00 & 2656.00 \\
\hline 21 & 1093.00 & 2421.00 & 1328.00 & 205.00 & 1974.00 & 1769.00 \\
\hline 22 & -143.00 & 2091.00 & 2234.00 & 396.00 & 2229.00 & 1833.00 \\
\hline 23 & 486.00 & 2180.00 & 1694.00 & -166.00 & 2248.00 & 2414.00 \\
\hline 24 & 1090.00 & 2916.00 & 1826.00 & 873.00 & 2815.00 & 1942.00 \\
\hline 25 & 619.00 & 2218.00 & 1599.00 & -144.00 & 2108.00 & 2252.00 \\
\hline 26 & -165.00 & 1907.00 & 2072.00 & 10.00 & 1927.00 & 1917.00 \\
\hline 27 & -388.00 & 1937.00 & 2325.00 & 281.00 & 1973.00 & 1692.00 \\
\hline 28 & 49.00 & 2751.00 & 2709.00 & 269.00 & 2123.00 & 1854.00 \\
\hline 29 & 457.00 & 2164.00 & 1767.00 & 297.00 & 2473.00 & 2176.00 \\
\hline 30 & 1406.00 & 3123.00 & 1717.00 & 245.00 & 2286.00 & 2041.00 \\
\hline average & 292.53 & 2513.10 & 2222.83 & 120.60 & 2444.50 & 2324.83 \\
\hline
\end{tabular}


at the level of the individual participant. The mean RT scores for PPs and SPs for participant 7 (boy) were $2444.50 \mathrm{msec}$ and $2324.83 \mathrm{msec}$, respectively. This yielded a difference of $120.60 \mathrm{msec}$. The difference score for participant 5 (girl) was $292.53 \mathrm{msec}$. The mean difference scores (between PP and SP trials) for the entire sample of boys as shown in Table 6 was 159.30, $t(14)=6.80, p<0.01$, while the mean difference scores for girls was $221.33 \mathrm{~ms}, t(14)=6.10, p<0.01$. The longer RT differences for girls did not reach significance, $t(28)=1.44, p>$ 0.05 , possibly due to the larger inter-individual variance compared to the adults in Experiment 1.

In order to get an overall picture of the age and gender differences, a two-way ANOVA for Age * Gender was performed on the difference scores (PP - SP) for the results of Experiments 1 and 2 altogether. Table 7 presents the means and standard deviations for the four subgroups. Significant main effects emerged for both gender and age, $\mathrm{F}(1,85)=17.30$ and $27.23, p<0.01$. The interaction term was not significant, $F(1,85)<1$. These findings are in line with Hypothesis 3 , showing shorter RT in adults and slower RT for females, possibly as a reflection

Table 6. RT means of 15 boys and 15 girls in the entire sets of $30 \mathrm{PP}$ and 30 SP conditions.

\begin{tabular}{|c|c|c|c|c|c|c|}
\hline participants & & girls & & & boys & \\
\hline 1 & difference & plural & singular & difference & plural & singular \\
\hline 2 & 365.50 & 3528.00 & 3162.50 & 320.00 & 4897.00 & 4577.00 \\
\hline 3 & 309.00 & 3924.00 & 3615.00 & 107.50 & 3979.50 & 3872.00 \\
\hline 4 & 240.00 & 2513.00 & 2273.00 & 123.00 & 2045.50 & 1922.00 \\
\hline 5 & 358.00 & 3198.00 & 2840.00 & 79.00 & 2071.00 & 1992.00 \\
\hline 6 & 115.00 & 2605.00 & 2490.00 & 85.00 & 2626.00 & 2541.00 \\
\hline 7 & 420.00 & 3884.00 & 3464.00 & 117.00 & 3294.00 & 3177.00 \\
\hline 8 & 166.00 & 3842.00 & 3676.00 & 119.50 & 2444.50 & 2325.00 \\
\hline 9 & 96.00 & 2679.00 & 2583.00 & 214.00 & 3357.00 & 3143.00 \\
\hline 10 & 80.50 & 2134.00 & 2053.50 & 327.00 & 4664.00 & 4337.00 \\
\hline 11 & 137.00 & 1942.00 & 1805.00 & 72.00 & 2844.00 & 2772.00 \\
\hline 12 & 232.00 & 2457.00 & 2225.00 & 125.00 & 2155.00 & 2030.00 \\
\hline 13 & 74.50 & 2254.50 & 2180.00 & 77.00 & 2770.00 & 2693.00 \\
\hline 14 & 98.50 & 2687.50 & 2589.00 & 211.00 & 2486.00 & 2275.00 \\
\hline 15 & 116.00 & 1967.00 & 1851.00 & 293.50 & 2163.00 & 1870.00 \\
\hline average & 512.00 & 2739.00 & 2227.00 & 120.00 & 2444.50 & 2325.00 \\
\hline participants & 221.33 & 2823.60 & 2602.26 & 159.36 & 2949.40 & 2790.06 \\
\hline
\end{tabular}

Table 7. PP - SP scores and related statistics for the inclusive age * Gender Model.

\begin{tabular}{ccccc}
\hline \multirow{2}{*}{ age } & \multicolumn{3}{c}{ young } & \multicolumn{3}{c}{ old } \\
\cline { 2 - 5 } & $\mathbf{M}$ & $\mathrm{SD}$ & $\mathbf{M}$ & $\mathrm{SD}$ \\
\hline male & 159.33 & 90.21 & 81.63 & 40.26 \\
Female & 221.33 & 140.49 & 114.96 & 51.80 \\
\hline
\end{tabular}


Table 8. Mean personal RT, $(\mathrm{PP}+\mathrm{SP}) / 2$ and Related Statistics for the Inclusive Age * Gender Model.

\begin{tabular}{ccccc}
\hline \multirow{2}{*}{ age } & \multicolumn{2}{r}{ young } & \multicolumn{3}{c}{ old } \\
\cline { 2 - 5 } & $\mathbf{M}$ & $\mathrm{SD}$ & $\mathbf{M}$ & $\mathrm{SD}$ \\
\hline male & 2869.73 & 893.39 & 2295.85 & 356.07 \\
Female & 2712.93 & 651.43 & 2324.13 & 380.78 \\
\hline
\end{tabular}

of tighter spontaneous learning to correct the wrong psycho-logical response request as a person gets older and a need for extra processing time in females.

A second ANOVA for Age ${ }^{*}$ Gender in Table 8 examined RT beyond PP and SP (personal mean of these two measures). In line with hypothesis 3 , longer RTs were found in young children, boys and girls, $F(1,53)=15.37, p<0.01$. The effect for Gender in this respect (overall RT) and the interaction were far from significance $(F<1)$.

\section{General Discussion}

Two experiments examined whether or not it takes native speakers of Hebrew longer to respond to appeals addressed in the plural than in the singular; and whether or not men and women differ in responses to plural forms; and (3) whether children (boys and girls) differ in their reaction times to plural and singular appeals. This study provides an initial support for the proposal that in Hebrew addressing an individual within a group in the second person plural form should facilitate an automatic correction manifested in longer reaction time than when the individual is addressed in the second person singular form. In addition, longer reaction times were found when female users of Hebrew as L1 were addressed in the second person masculine form. Finally, support was also documented for the hypothesis that such correction is acquired during the (Hebrew) language acquisition process. This hypothesis received further support from an exploratory experiment showing that English-speaking children do not show evidence for this correction when responding to requests in second person masculine form.

\section{Language and Cognition}

With regard to the hypothesized correcting mechanism, these findings support the assumption that Hebrew native speakers acquire an automatic correcting mechanism that develops as part of a cognitive strategy. That is to the extent that the individual no longer expects to be addressed as such when he or she is part of a group. According to the "strong correspondence hypothesis" (Radford, 1990), linguistic structures must necessarily correspond to cognitive structures in language processing. The lack of such correspondence is implied from the present findings, now state exactly how the findings show a lack of correspondence between comprehension of masculine plural and the cognitive structure. This mismatch/asymmetry renders the individual incapable of correctly processing a given grammatical structure. 
Children gradually acquire language-processing mechanisms appropriate to the grammatical structures of their native language. Hypothetically, this process takes place through ongoing self-examination in response to exposure that allows the child to learn to avoid psychologically incompatible grammatical structures. At the same time, this process relies on inherent grammatical knowledge (Gold, 1967). The present study lends support to this assumption by revealing longer processing times for children, than for adults, in response to second person plural appeals among children.

The process of becoming accustomed to linguistic structures during late infancy and early childhood mobilizes/recruits cognitive sensitivity to incompatibility of syntactic structures. Repeated exposure to second person plural appeals may force the young listener's processing mechanism to cope with the literal meaning of a single person-the speaker's intention. This putative process of separating literal meaning from implied intention was presumably reflected in the finding of longer RTs to appeals in the plural than in the singular form.

Generative theories show that the rules of grammar are congenital and serve to assist in identifying correct manners of speech through generalization (Chomsky, 1965). It appears that the correction mechanism, traces of which are detectable in the present findings, reflect two characteristics of language learning: learning to disregard psycholinguistic incompatibilities and the notion that addressing an individual in the plural form is grammatically flawed.

In terms of gender, it was found that when a woman or a young girl whose native language is Hebrew was addressed as an individual within a group in masculine plural form, her RTs were longer in comparison to those of males. The routine in which a native Hebrew speaking girl, and later on women, is required to accept and internalize a linguistic practice which ignores her gender can be argued to facilitate a disconnection between her feminine identity and her native language.

This sort of disconnection is constantly signposted in various ways. Women themselves even tend to address others in the second person masculine plural form, even when she is speaking to a woman or women, for example, the $\mathrm{He}$ brew request "דמצעל ראת" (imagine). When we drew the attention of a girl or woman to this practice, the first and most frequent response was defensive, i.e., "it doesn't bother me". This indicates an acceptance of female identity that lacks full representation of one of the most important components of human identity, namely the native language.

\section{Methodological Considerations}

The present study relied on large amounts of data from relatively few participants. This approach shows the priority of individual analyses. The design required multiple responses of each participant to each manipulation condition-requests in the form of second person plural masculine and requests in the form of second person singular masculine $(30+30)$. This quality of the design makes the contribution of each participant more reliable, in other words more 
powerful in a way which is not related to by the conventional power test, recalling that in many traditional experimental designs the output of each participant is one response or mostly an average of very few responses.

One may also argue that the laboratory-like nature of the present study produces a sterile socio-cognitive experience that in turn generates a sterile response, and that this combination creates a situation dissimilar to that which the research question seeks to address. This might jeopardize internal validity and possibly mundane validity as well (Campbell \& Stanley, 1963; Kelly, 2007). Nevertheless, it is nearly impossible to come up with an offer of any jeopardizing explanation for the clear-cut finding of extra processing time in Hebrew as L1 speaking men and boys, and extra + processing time in women and girls in conditions of responses to second person masculine addresses. Correction process is nearly the only viable and most parsimonious account for these findings.

There is a need, however, to conduct systematic empirical examination of the present findings' external validity. First, by drawing a systematic experimental distinction between the reactions of men and women to both modes of address to individuals in conditions of a bi-factorial model - plural/singular * masculine/female $(2 * 2)$. Such systematic study should naturally consider (perhaps as a covariant) the relatively low prevalence of addressing an individual within a group in second person female form.

With regard to internal validity (Campbell \& Stanley, 1963), the nature of the participant-experimenter encounter in this study should be noted. A necessary condition for the success of the manipulation was a deception procedure which was a variation of Milgram's behavioral study of obedience (McLeod, 2017; Milgram, 1963), where the participant is led to believe that he or she is part of a group of participants, located in various corners of the laboratory. The experimenter in the present study made an effort to convince the participant that there are other participants around prior of the formal part of the session. To reinforce this belief, several times during the session she faked messages to the "other" participants.

Another limitation of the present findings is the use of RT as an indirect measure of cognitive processing. Ideally, direct inspection of correcting processes in the conditions of psycho logical linguistic incompatibility is desirable. However, while such observations could become possible in the future (possibly next decade) for now we can recommend the use of other indirect measures of brain processing, such as $\mathrm{PMRI}$ and EEG, to enable cross validation of the findings.

While the results reveal meaningful manipulation effects, farther experimentation should take into account the following recommendations. Firstly, recordings of "other participants" comments and questions should be part of the instruction phase. Moreover, future experimentation should compare two speaker-listener conditions. In one condition, similar to the present procedure, the participant should be lead to believe that he or she is part of a group of participants, as was the case in the present study. Such procedure, however, is quite in- 
frequent in daily Hebrew speaker-listeners message submission, due to this language's inability to enable speaker's use of second person single form of appeal to individuals within a group (e.g., "imagine" or "think of" in English). This means that the present findings are quite limited in terms of mundane validity as well as external validity.

In a control experiment, a partial replication of the present study's procedure should take place. In one condition, second person plural masculine form, the participant should be lead to believe that he or she is part of a group, as is the case in the present study. In a more viable mundane-wise control condition the (same) participant should be lead to believe that he or she is the only receiver of the speaker's messages. Hypothetically, the findings of such study should yield more significant results than those of the present study, simply due to the greater fit to real-life communication. In terms of external validity, a partial replication of this sort of design, which manipulates the difference between second person plural/singular masculine and feminine form is strongly recommended.

With regard to sampling and inclusiveness it should be noted that the samples of participants were quite homogeneous in terms of age of the adult participants (30 - 38) and the children (5 - 6) and in terms of socio-economic status (middle class), which means an adequate level of linguistic capabilities of the participants. Of course, this sort of homogeneity limits inclusiveness. However, one quality of the findings should be taken into account. That is, a thorough and detailed inspection of the participants' responses shows extra processing time in each of the 30 "PP - PS" pairs (assumingly a sort of speech cost). This aspect of the findings reinforces the assumption regarding their inclusiveness.

In terms of measurement, the drawback of using RT as an indirect reflection of cognitive processes is that it measures the reverberation, as it were, of processes that occur in the brain rather than the processes themselves. Its advantage is that it has been rigorously tested for validity (Jiang, 2012), and this demonstrates its capacity to reflect differences that are of theoretical significance. It is therefore recommended to use this measure to examine implications of the present findings. Use of fMRI to identify various stages of the automatic related correction process and interactions between them is recommended as well.

\section{Other Languages with a Special reference to English}

A further topic worthy of systematic study is the relevance of the findings of the present study for the Hebrew language to other languages, Arabic in particular, that feature different modes of addressing individuals within a group in second person plural form. It would also be worthwhile examining this issue with regard to the way in which an individual is addressed in Latin based languages, German in particular, in the third person form. It is particularly important to examine how children whose native language is Hebrew (and possibly Arabic) learn to make cognitive corrections to such psycho-logically inappropriate addresses. Does this learning acquire functional autonomy at a certain 
Table 9. SPPM - SPSM scores and related statistics for the seven speakers of English as L1.

\begin{tabular}{|c|c|c|c|}
\hline participant & difference & plural & singular \\
\hline 1 & 1104 & 3204 & 2100 \\
\hline 2 & -500 & 2241 & 2741 \\
\hline 3 & -295 & 1913 & 2208 \\
\hline 4 & 73 & 1939 & 1866 \\
\hline 5 & -2569 & 2362 & 2146 \\
\hline 6 & 380 & 2860 & 2480 \\
\hline 7 & -248 & 2227 & 2475 \\
\hline 8 & 886 & 3111 & 2225 \\
\hline 9 & -106 & 2199 & 2305 \\
\hline 10 & -106 & 2551 & 1889 \\
\hline 11 & -5 & 2095 & 2100 \\
\hline 12 & 717 & 2381 & 1664 \\
\hline 13 & -289 & 1763 & 2052 \\
\hline 14 & -386 & 1766 & 2152 \\
\hline 15 & -172 & 1925 & 2097 \\
\hline 16 & -152 & 1875 & 2027 \\
\hline 17 & 328 & 2082 & 1754 \\
\hline 18 & 242 & 2074 & 1832 \\
\hline 19 & 356 & 2280 & 1924 \\
\hline 20 & 391 & 1900 & 1509 \\
\hline 21 & 612 & 2184 & 1572 \\
\hline 22 & -776 & 1835 & 2611 \\
\hline 23 & 522 & 2094 & 1572 \\
\hline 24 & -16 & 1934 & 1950 \\
\hline 25 & -728 & 2037 & 2765 \\
\hline 26 & -231 & 1874 & 2105 \\
\hline 27 & -277 & 2039 & 2316 \\
\hline 28 & -22 & 1778 & 1800 \\
\hline 29 & -665 & 1867 & 2532 \\
\hline 30 & 975 & 2756 & 1781 \\
\hline average & -6.3 & 2140.29 & 2055.59 \\
\hline
\end{tabular}

age, and is there a difference in this respect between boys and girls, as implies from the present findings?

Possibly, a replication of the present design on users of English as L1 and Hebrew as L2 who live in Israel and use Hebrew on a daily basis should be the next empirical step. The results of such study should provide refutation or support for the present study's presumption of learned corrective processes in users of Hebrew as L1. For the crucial importance of this question, a pre-preliminary examination of this issue was already conducted, as described briefly below. 
The participants were 10 women (ages 30 - 40) who leave in Israel, all born in English speaking countries. English was L1 and Hebrew L2 for seven of them while the remaining three were bi-lingual-English and Hebrew. The results for the three bilinguals resembled the findings for experiment 1 among speakers of Hebrew as L1. Their personal PP - SP differences are 122, 276, and $104 \mathrm{~ms}$ (recalling that the corresponding women's mean difference in experiment 1 is $114.96 \mathrm{~ms}$ ). Most importantly, as can be seen in Table 9, participant by participant, there is no indication for PP - SP difference in the results of the seven speakers of English as L1, as can be seen in Table 9. The mean related RT difference is $2189.00-2143.00=46 \mathrm{~ms}, t(6)<1$.

These pre-preliminary results seem to point to the viability of the correction presumption. Possibly, due to a carry-over of the quasi-solution that the English language provides for psycho-logical faults for which there is no solution in $\mathrm{He}$ brew. It should be noted that while the very small interpersonal variance found among the seven participants bolsters our confidence in the external validity of the finding, extended replications are required.

\section{Two Other Notable Issues}

What about the speaker? Can the unique psycho-logical address discussed here affect the speaker? One may surmise that an address directed at every individual within a group couched in a way that disregards the distinction between individuals is likely to lead the speaker to differentiate himself or herself from a generalized "rest of the world." This is an anti-empathetic type of address likely to stimulate egocentricity and a tendency to fail to recognize the individuality of other personae. Hypothetically, in Hebrew the repeated use of second person plural form by lecturers, teachers broadcasters and many other speakers who belong to this category should facilitate a view of "me in front of the rest of the world." This implication might prove fruitful theoretically and empirically.

Last, but not least, top-down (i.e., by the Israeli Academy for the Hebrew Language) search for a lexical and syntactic alternative to the no-choice necessity to address individuals within a group in second person male plural form is recommended. Simply, for the psychological need to eradicate or at least moderate the problem that the present study has pointed at. Finally, with all due respect for current psychological, linguistic or psycholinguistic fields and sub-fields we were not able to fit the corrective psycho logical phenomenon dealt with in this study in any of them. So, we would suggest to think of another field or sub-field called "Psycho-Logical Incompatibility" or "Corrective Language Processing.

\section{Conflicts of Interest}

The authors declare no conflicts of interest regarding the publication of this paper.

\section{References}

Ariel, M., \& Giora, R. (1998). A Self versus Other Point of View in Language: Redefining 
Femininity and Masculinity. International Journal of Society of Language, 129, 59-86. https://doi.org/10.1515/ijsl.1998.129.59

Arnold, J. E., Eisenband, J. G., Brown-Schmidt, S., \& Trueswell, J. C. (2000). The Rapid Use of Gender Information: Evidence of the Time Course for Pronoun Resolution from Eye Tracking. Cognition, 76, 13-26. https://doi.org/10.1016/S0010-0277(00)00073-1

Austin, J. L. (1962). How to Things with Words. Oxford: Oxford University Press.

Bandura, A. (1986). Social Foundations of Thought and Action: A Social Cognitive Theory. Englewood Cliffs, NJ: Prentice-Hall.

Baranowski, M. (2002). Current Usage of the Epicene Pronoun in Written English. Journal of Sociolinguistics, 6, 378-395.

Beebe, B., \& Lachmann, F. M. (1988). The Contribution of Mother-Infant Mutual Influence to the Origins of Self- and Object Representations. Psychoanalytic Psychology, 5, 305-337. https://doi.org/10.1037/0736-9735.5.4.305

Blackmer, E. R., \& Mitton, J. L. (1991). Theories of Monitoring and the Timing of Repairs in Spontaneous Speech. Cognition, 39, 173-194. https://doi.org/10.1016/0010-0277(91)90052-6

Campbell, D. T., \& Stanley, J. C. (1963). Experimental and quasi-Experimental designs for research. Boston, MA: Houston Mifflin.

Chomsky, N. (1965). Some Controversial Questions in Phonological Theory. Journal of linguistics, 1, 97-138.

Clark, H. H., \& Lucy, P. (1975). Understanding What Is Meant from What Is Said: A Study in Conversationally Conveyed Requests. Journal of Verbal Learning and Verbal Behavior, 14, 56-72. https://doi.org/10.1016/S0022-5371(75)80006-5

Doherty, A., \& Conklin, K. (2017). How Gender-Expectancy Affects the Processing of “Them”. The Quarterly Journal of Experimental Psychology, 70, 718-735. https://doi.org/10.1080/17470218.2016.1154582

Foertsch, J., \& Gernsbacher, M. A. (1997). In Search of Gender Neutrality: Is Singular They a Cognitively Efficient Substitute for Generic He? Psychological Science, 8, 106-111. https://doi.org/10.1111/j.1467-9280.1997.tb00691.x

Gold, E. M. (1967). Language Identification in the Limit. Information and Control, 10, 447-474. https://doi.org/10.1016/S0019-9958(67)91165-5

Grice, H. M. (1967). The Logic of Conversation. William James Lectures. Cambridge, MA: Harvard University.

Jarvikivi, J., van Gompel, R. P. G., Hyona, J., \& Bertram, R. (2005). Ambiguous Pronoun resolution: Contrasting the First-Mention and Subject-Preference Accounts. Psychology Science, 16, 260-264. https://doi.org/10.1111/j.0956-7976.2005.01525.x

Jiang, N. (2012). Conducting Reaction Time Research in Second Language Studies. New York: Routledge. https://doi.org/10.4324/9780203146255

Kashima, E. S., \& Kashima, Y. (1998). Culture and Language: The Case of Cultural Dimensions and Personal Pronoun Use. Journal of Cross-Cultural Psychology, 29, 461-486. https://doi.org/10.1177/0022022198293005

Kasl, S. V., \& Mahl, G. E. (1987). Speech Disturbances and Experimentally Induced Anxiety. In G. F. Mahl (Ed.), Exploration in Nonverbal and Vocal Behavior (pp. 203-213). New York: Psychology Press.

Kelly, J. R. (2007). Mundane Realism. In R. F. Baumeister, \& K. D. Vohs (Eds.), Encyclopedia of Social Psychology (p. 329). Thousand Oaks, CA: Sage.

Kerr, J. S., \& Underwood, G. (1984). Fixation Time on Anaphoric Pronouns Decreases with Contiguity of Reference. In A. G. Gale, \& E. Johnson (Eds.), Theoretical and Ap- 
plied Aspects of Eye Movement Research (pp. 195-202). Amsterdam: North Holland.

Kraut, R. E. (1973). Effects of Social Labeling on Giving to Charity. Journal of Experimental Social Psychology, 9, 551-562. https://doi.org/10.1016/0022-1031(73)90037-1

MacDonald, M. C., \& MacWhinney, B. (1990). Measuring Inhibition and Facilitation from Pronouns. Journal of Memory and Language, 29, 469-492. https://doi.org/10.1016/0749-596X(90)90067-A

McLeod, S. A. (2017) The Milgram Shock Experiment: Simply Psychology. https://www.simplypsychology.org/milgram.html

Meyers, M. W. (1990). Current Generic Pronoun Usage: An Empirical Study. American Speech, 65, 228-237. https://doi.org/10.2307/455911

Milgram, S. (1963). Behavioral Study of Obedience. Journal of Abnormal and Social Psychology, 67, 371-378. https://doi.org/10.1037/h0040525

Na, J., \& Choi, I. (2009). Culture and First-Person Pronouns. Personality and Social Psychology Bulletin, 35, 1492-1499. https://doi.org/10.1177/0146167209343810

Nieuwland, M. S., \& Van Berkum, J. J. A. (2006). Individual Differences and Contextual Bias in Pronoun Resolution: Evidence from ERPs. Brain Research, 1118, 155-167. https://doi.org/10.1016/j.brainres.2006.08.022

Radford, A. (1990). The Syntax of Nominal Argument in Early Child English. Language Acquisition, 1, 195-223. https://doi.org/10.1207/s15327817la0103_1

Sanford, A. J. S., Sanford, A. J., Molle, J., \& Emmott, C. (2010). Shallow Processing and Attention Capture in Written and Spoken Discourse. Discourse Processes, 42, 109-103. https://doi.org/10.1207/s15326950dp4202_2

Sanford, A. J., \& Filik, R. (2007). "They" as a Gender Unspecified Singular Pronoun: Eye-Tracking Reveals a Processing Cost. Quarterly Journal of Experimental Psychology, 60, 171-178. https://doi.org/10.1080/17470210600973390

Schmitt, B. M., Lamers, M., \& Munte, T. F. (2002). Electrophysiological Estimates of Biological and Syntactic Gender Violation during Pronoun Processing. Cognition and Brain Research, 14, 333-346. https://doi.org/10.1016/S0926-6410(02)00136-2

Searle, J. R. (1965). What Is a Speech Act? In M. Black (Ed.), Philosophy in America (pp. 221-240). London: Allen and Unwin.

Stern, D. N. (1985). The Interpersonal World of the Infant. New York: Basic Books.

Terry, D. J., Hogg, M. A., \& White, K. M. (1999). The Theory of Planned Behavior: Self-Identity, Social Identity, and Group Norms. British Journal of Social Psychology, 38, 225-244. https://doi.org/10.1348/014466699164149

Tobin, Y. (2001). Gender Switch in Modern Hebrew. In M. Hellinger, \& H. Busmann (Eds.), Gender across Languages: The Linguistic Representation of Women and Men (Vol. 1, pp. 177-199). Amsterdam: John Benjamins Publishing Company. https://doi.org/10.1075/impact.9.13tob

Wilson, D., \& Sperber, D. (2006). Relevance Theory. In R. N. Horn, \& G. Ward (Eds.), The Handbook of Pragmatics (pp. 607-633). Oxford: Blackwell Publishing.

Winnicott, W. D. (1960). The Theory of the Parent-Infant Relationship. International Journal of Psycho-Analysis, 41, 585-595.

Ziller, R. C. (1973). The Social Self. New York: Pergamon. 